\title{
28 Research Suare \\ The Blood level of Thioredoxin 1 as a Supporting Biomarker in the Detection of Breast Cancer
}

\section{Youn Ju Lee}

Chungnam National University Sejong Hospital

\section{Young Kim}

E\&S Healthcare

\section{Bo Bae Choi}

Chungnam National University Hospital

\section{Je Ryong Kim}

Chungnam National University Hospital

\section{Hye Mi Ko}

Chungnam National University Hospital

Kyoung Hoon Suh ( $\square$ one@ens-h.com )

Pai Chai University https://orcid.org/0000-0003-2301-5718

\section{Jin Sun Lee}

Chungnam National University Hospital

\section{Research article}

Keywords: Thioredoxin 1, Breast Cancer, Diagnostics, Mammography, Sensitivity, Specificity, Blood, Biomarker Posted Date: February 8th, 2021

DOI: https://doi.org/10.21203/rs.3.rs-165194/v1

License: @ (i) This work is licensed under a Creative Commons Attribution 4.0 International License. Read Full License

Version of Record: A version of this preprint was published at BMC Cancer on January 3rd, 2022. See the published version at https://doi.org/10.1186/s12885-021-09055-1. 


\section{Abstract}

Background: It has been a long-time unmet need to have a means to detect breast cancer (BC) using blood. Although mammography is accepted as the gold standard for screening, thus, playing a role to reduce death from breast cancer, a blood-based diagnostic can complement mammography and assist in the accurate diagnosis of BC. We have previously reported the possible use of thioredoxin 1 (Trx1) in serum as a novel means to detect $\mathrm{BC}$. In the present study, we validated the clinical utility of Trx 1 to detect BC by testing sera from biopsy-confirmed cancer patients, and normal healthy people.

Methods: We have generated monoclonal antibodies against Trx1 and developed an ELISA kit that can quantitate Trx 1 in sera. The level of Trx 1 was determined in each serum from normal healthy women $(n=114)$, as well as patients with $B C(n=106)$, and other types of cancers $(n=74)$ including cervical, lung, stomach, colorectal, and thyroid cancer. The sera from BC patients were collected according to their age and cancer stage. Several pathological and molecular aspects of BC were analyzed along with the Trx1 levels of BC patients. Test results were compared to those from mammography. Each test was duplicated, and test results were analyzed by ROC analysis, one-way ANOVA tests, and unpaired t-tests.

Results: The mean level of Trx1 from normal women's sera was $5.45 \pm 4.16( \pm S D) \mathrm{U} / \mathrm{ml}$ and that from $B C$ was $21.96 \pm 6.79 \mathrm{U} / \mathrm{ml}$. The difference between these two values was large enough to distinguish $\mathrm{BC}$ sera from healthy sera with a sensitivity of $94.3 \%$ and specificity of $94.7 \%$ (AUC $0.985, p<0.0001$ ). Most Trx 1 levels from BC patients' sera were higher than the cut-off value of $14.13 \mathrm{Unit} / \mathrm{ml}$ regardless of age, stage, histological grade, type, and specific receptors' expression profile of BC. The blood levels of Trx 1 from the group of patients with other types of cancers $(2.70 \pm 2.01 \mathrm{U} / \mathrm{ml})$ was low to be distinguishable from BC. Trx 1 level could rescue most of misreading incompleteness of mammography.

Conclusion: These results indicated that the blood level of Trx 1 could be an effective and accurate means to assist or complement current BC diagnostic modalities.

\section{Introduction}

It is well-known that BC causes the most malignant tumors in women. A worldwide study showed that, in 2018 , an estimated 2.1 million women were newly diagnosed with BC and more than 600,000 women with BC died [1]. It is likely that incidence is three times higher in well-developed regions than in low-developed or developing regions [2]. On the other hand, mortality of $\mathrm{BC}$ is generally higher in many low-developed and developing countries despite their lower incidence. It seems to be because of delayed presentation, late stage at diagnosis and limited access to treatment. This reflects both the risk factors from their lifestyles and the availability and utility of proper BC screening [3-6].

Breast cancer is generally diagnosed by screening systems such as imaging modalities including mammography and ultrasound scanning. Although each method has its own pros and cons, mammography is a primary screening tool for $\mathrm{BC}$ and has demonstrated its utility to reduce mortality of $\mathrm{BC}$ compared to other imaging diagnostic methods [7]. The World Health Organization acknowledges that mammography is currently the only satisfactory BC screening method [8]. Although it is known that mammography significantly reduces mortality in women over 50 years of age, it is not as helpful for younger women $[9,10]$. The current most 
advanced digital mammography systems are not perfect showing values of sensitivity and specificity to detect BC of $90 \%$ or below $[11,12]$. It was shown that the sensitivity and specificity of digital mammography were $85 \%$ and $90 \%$, respectively, in women aged less than 50 years and in pre- or perimenopausal females with non-dense breasts [13]. When it comes to dense breasts, the performance of mammography shows even lower numbers [12]. Although the mammography system is regarded currently as the best method to detect BC as early as possible, it also has disadvantages. Most mammography equipment is installed in specific hospitals as immobile instruments so that women must take a trip to visit a facility where the machine is available. This situation could cause hesitation or even giving up the foregoing of mammography for screening purposes. Physical and mental discomfort experienced in prior mammography sessions also worsen the situation. The limited accessibility to mammography in developing countries is another major obstacle to the early detection of $\mathrm{BC}$. Therefore, it is desirable to have a means that complements mammography, and thus mitigates current problems and limits of the mammography-oriented screening system.

In addition to screening of $\mathrm{BC}$ by imaging technologies, discovery of biomarkers by analyzing various body fluids draws attention for their potential usage in easy and rapid detection of cancer. A study of 1,005 patients to evaluate the clinical utility of analyzing specific circulating proteins and mutation in cell-free DNA for early detection of eight types of cancer from blood has been undertaken [14]. Although it showed sensitivities for certain types of cancer ranged from $69-98 \%$, that for $\mathrm{BC}$ was little more than $30 \%$. Recently, another massive study with 6,689 participants attempted to validate whether targeted methylation analysis of cell-free DNA was good for early detection of certain types of cancer [15]. It indicated that sensitivity for twelve cancer types was $67.3 \%$, but breast cancer was not included. Despite tremendous investment in liquid biopsy technology as an innovative means to discover novel biomarkers that are promising for the detection of $\mathrm{BC}$, there is no obvious candidate. That is the reason why most biomarker tests currently being used are for theranostic and prognostic purposes, not for the detection of BC. Typically, specific receptor expression profiling tests, including those for estrogen receptor (ER), progesterone receptor (PR) and human epidermal growth factor receptor 2 (HER2), are recognized by international guidelines as predictive factors indispensable for invasive $\mathrm{BC}$ therapy decisionmaking $[16,17]$. Among the gene analyzing tests, mutation analysis of BRCA genes [18] is one of the most widely adopted to predict the risk of $B C$ in advance, along with the MammaPrint and Oncotype Dx tests $[19,20]$. Cancer antigen $15-3$ (CA15-3) is for monitoring outcomes of treatment or recurrence of $B C[21,22]$. Carcinoembryonic antigen (CEA) is occasionally also used to detect BC from blood [23]. However, there is as of yet no biomarker test using blood to detect $\mathrm{BC}$ with high sensitivity and specificity.

We have reported that a member of the antioxidative protein families, thioredoxin 1 (Trx1), exhibited a close relationship between its level in serum and BC occurrence [24, 25]. The blood levels of Trx 1 from BC patients were higher than those from normal healthy women. Its sensitivity and specificity to detect BC were higher than those of CA15-3 and CEA. Since the blood level of Trx 1 could be a novel standard to evaluate the current risk of $\mathrm{BC}$, we have investigated the clinical utility of it as a biomarker to detect $\mathrm{BC}$ by testing sera from normal healthy women, patients with $\mathrm{BC}$, and patients with other types of cancer. The level of Trx1 in blood was tested according to the age of $\mathrm{BC}$ patients, as well as the stage, types, and grade of their BC. A comparison analysis with other types of cancer to examine the selectivity of Trx 1 for BC was also carried out. In addition, the Trx 1 level was analyzed, along with mammograms, to assess how well the Trx 1 level could complement or assist mammography for the better detection of BC. It was hypothesized that the level of Trx 1 in blood was likely to be 
a novel and specific means to detect BC that can compensate for or mitigate the limitations of current $B C$ screening modalities.

\section{Methods}

Study design The sera were collected from normal healthy Korean women $(n=114)$, as well as patients with BC $(n=106)$, and patients with other types of cancers $(n=74$, total) including cervical $(n=17)$, lung $(n=30)$, stomach $(n=9)$, colorectal $(n=14)$, and thyroid $(n=4)$ cancer. Since the number of patients with each of the five types of cancers was relatively low, they were combined and analyzed as one group. The level of Trx 1 from each serum was determined by an ELISA kit, DxMe BC (E\&S Healthcare, BCE01, Korea). Serum from each cancer patient was collected retrospectively. Candidates from BC patients were selected by the results of their mammography, biopsy, ultrasound scanning if available, and a physician's final confirmation. Those from other types of cancer were selected according to a physician's final confirmation of the corresponding cancer. The BC patients were grouped according to their clinical information and BC characteristics. Attention was paid to distribute a reasonable number of patients to each group. The Trx1 test results were compared with the readings of mammograms to assess its accuracy and capacity to complement the imaging diagnosis for $\mathrm{BC}$. All blood sample collection was compliant with the standards of an ethical committee from Chungnam National University Hospital in Daejeon, Korea (CNUH 2107-12-035), and study with those blood samples was conducted in accordance with the relevant guidelines and regulations.

Serum preparation The blood samples used in this study were retrospectively collected and deposited at the Human Body Resources Bank of Chungnam National University Hospital. When a patient consented to donate blood, a designated phlebotomist withdrew blood from the cephalic vein into serum separating tubes (BD Vacutainer, SST ${ }^{\mathrm{TM}}$ II Advance Plus Blood Collection Tubes). After standing at room temperature for blood clotting, the serum separating tubes were centrifuged at 1,000 x g for 15 minutes. The serum portion of the supernatant was collected and transferred to cryogenic tubes. The sera were stored at $-70^{\circ} \mathrm{C}$ until use.

Quantitation of Trx1 in serum We have generated a pair of monoclonal antibodies against Trx1. By using these antibodies, DxMe BC ELISA kit (E\&S Healthcare) was developed to quantitate Trx1 from sera. The kit was based on sandwich ELISA technology, and the test procedure followed the instruction of the kit that was modified from the protocol described elsewhere $[24,26]$. The level of Trx 1 in serum was calculated from the standard curve that was generated using pure recombinant human Trx1 protein.

Comparison analysis with mammography In order to evaluate the ability of the $\operatorname{Trx} 1$ test to complement or mitigate the limitation of current mammography, a comparison study was carried out. The blood level of Trx 1 of each normal healthy woman and breast cancer patient was measured as described above and analyzed along with a radiologic report of the corresponding mammogram by a breast radiologist with twelve years of experience. Among normal women and breast cancer patients who had been confirmed as having BC by biopsy, only the ones who had mammograms approved by a physician were involved in the analysis. Therefore, the blood level of Trx1 and mammograms from 42 normal women and 103 BC patients were finally analyzed.

Statistical analysis Each test was duplicated and performed more than two times. The sensitivity and specificity were calculated by ROC curve analysis with a predetermined cut-off value. The data were further analyzed by Kruskal-Wallis tests, one-way ANOVA tests, and unpaired t-tests when necessary. Statistical 
analysis was performed using MedCalc (ver.19.1.5, MedCalc Software Ltd.) and Prism 6 (GraphPad) software. It was regarded as statistically significant when $p<0.005$.

\section{Results}

\section{Breast cancer patients}

A total of 106 patients who had been confirmed to have BC by physicians were recruited, and their mean age was close to 50 . Most BC patients were at stage $2(N=50,47.2 \%)$ and the rest of them were at stage $1(n=37$, $34.9 \%)$, stage $3(n=15,14.2 \%)$ and stage 0 and 4 ( $n=2$ each, $1.9 \%$ each) (Table 1$)$. The stage of the BC patients seemed relatively well distributed, representative of the actual BC patient population in Korea. More than $86 \%$ of the patients had invasive ductal carcinoma (IDC, $n=92$ ) and each of the other types of BC such as ductal carcinoma in-situ (DCIS), invasive lobular carcinoma (ILC), invasive micropapillary carcinoma (IMPC), mucinous carcinoma (MC), and invasive tubular carcinoma (ITC), were low in number from 1 to 5.

Table 1

Participants of the study and basic clinical information of breast cancer patients

\begin{tabular}{|c|c|c|c|c|c|c|c|}
\hline \multicolumn{2}{|l|}{ Participants ${ }^{1}$} & \multicolumn{6}{|c|}{ Breast cancer patients ${ }^{2}$} \\
\hline Serum sources & No. & Stage & No. & $\%$ & Type & No. & $\%$ \\
\hline Healthy normal women & 114 & 0 & 2 & 1.9 & DCIS & 2 & 1.9 \\
\hline Breast cancer & 106 & 1 & 37 & 35.0 & IDC & 92 & 86.8 \\
\hline Lung cancer & 30 & 2 & 50 & 47.2 & ILC & 5 & 4.7 \\
\hline Cervical cancer & 17 & 3 & 15 & 14.2 & $\mathrm{MC}$ & 5 & 4.7 \\
\hline Colorectal cancer & 14 & 4 & 2 & 1.9 & IMPC & 1 & 0.9 \\
\hline Stomach cancer & 9 & & & & ITC & 1 & 0.9 \\
\hline \multirow[t]{7}{*}{ Thyroid cancer } & 4 & Histological grade & & & & & \\
\hline & & 1 & 24 & 22.6 & \multicolumn{3}{|c|}{ Molecular subtype } \\
\hline & & 2 & 51 & 48.1 & Luminal A & 47 & 44.3 \\
\hline & & 3 & 31 & 29.3 & Luminal B & 37 & 34.9 \\
\hline & & Proliferation(Ki67) & & & TNBC & 13 & 12.3 \\
\hline & & $<15 \%$ & 49 & 46.2 & HER2-enriched & 9 & 8.5 \\
\hline & & $\geq 15 \%$ & 57 & 53.8 & & & \\
\hline
\end{tabular}

${ }^{1}$ Sera from designated participants were obtained from Chung Nam National University Hospital with ethical committee approval.

2 The clinical information of breast cancer patients was classified according to breast cancer stage, histological grade, proliferation activity, type, and molecular subtype. DCIS, ductal carcinoma in situ; IDC, invasive lobular 
carcinoma; MC, mucinous carcinoma; IMPC, invasive micropapillary carcinoma; ITC, invasive tubular carcinoma; TNBC, triple-negative breast cancer.

Almost half of the patients showed histological grade $2(\mathrm{~N}=51,48.1 \%)$, and grades 1 and 3 showed similar numbers. Luminal $A$ and $B$ composed almost $80 \%$ of patients and triple negative breast cancer (TNBC, $12.3 \%)$ and HER2-enriched (8.5\%) comprised the rest. More than $53 \%$ of the patients presented higher cancer cell proliferation activity ( $\geq 15 \%$ ) estimated by the Ki67 test. Each BC patient went through necessary tests, such as mammography, ultrasonic scanning, immunohistochemistry, gene expression of specific receptors, or MRI when necessary. A dataset of the breast cancer patients' clinicopathological information is shown in Table 2. 
Table 2

Clinicopathological information of breast cancer patients.

\begin{tabular}{|c|c|c|c|c|c|c|c|c|c|c|c|c|}
\hline Patient No. & Age & Trx1(U/ml) & Type & $\mathrm{HG}^{*}$ & $T^{*}$ & $\mathbf{N}^{*}$ & $M^{*}$ & Stage & $E R^{*}$ & $\mathrm{PR}^{*}$ & HER2* & $\mathrm{Ki} 67^{*}$ \\
\hline BC001 & 46 & 3.84 & IDC & 2 & 2 & 1 & 0 & $2 B$ & 3 & 3 & 1 & 20 \\
\hline BC002 & 42 & 22.38 & IDC & 2 & 1 & 2 & 0 & $3 A$ & 3 & 3 & 3 & 60 \\
\hline $\mathrm{BCO03}$ & 57 & 24.87 & IDC & 1 & 1 & 0 & 0 & $1 \mathrm{~A}$ & 3 & 0 & 3 & 5 \\
\hline BCO04 & 45 & 18.71 & IDC & 2 & 1 & 1 & 0 & $1 B$ & 3 & 3 & 1 & 2 \\
\hline BC005 & 45 & 24.37 & IDC & 2 & 2 & 0 & 0 & $2 A$ & 2 & 3 & 1 & 40 \\
\hline BC006 & 44 & 19.07 & IMPC & 1 & 2 & 3 & 0 & $3 C$ & 3 & 3 & 1 & 40 \\
\hline BC007 & 52 & 22.46 & IDC & 1 & 1 & 0 & 0 & $1 \mathrm{~A}$ & 3 & 3 & 1 & 2 \\
\hline BC008 & 53 & 30.38 & ILC & 2 & 2 & 0 & 0 & $2 \mathrm{~A}$ & 3 & 3 & 1 & 1 \\
\hline BC009 & 57 & 22.24 & ILC & 2 & 2 & 0 & 0 & $2 A$ & 3 & 3 & 1 & 5 \\
\hline BC010 & 55 & 17.12 & IDC & 2 & 1 & 0 & 0 & $1 \mathrm{~A}$ & 3 & 3 & 1 & 25 \\
\hline BC011 & 49 & 34.72 & IDC & 2 & 2 & 1 & 0 & $2 B$ & 3 & 3 & 1 & 30 \\
\hline BC012 & 41 & 23.10 & IDC & 3 & 2 & 1 & 0 & $2 B$ & 0 & 0 & 1 & 90 \\
\hline BC013 & 40 & 19.06 & IDC & 2 & 2 & 1 & 0 & $2 B$ & 2 & 3 & 1 & 5 \\
\hline BC014 & 50 & 16.47 & IDC & 2 & 2 & 3 & 0 & $3 C$ & 3 & 3 & 1 & 5 \\
\hline BC015 & 48 & 27.63 & IDC & 2 & 1 & 0 & 0 & $1 \mathrm{~A}$ & 3 & 3 & 3 & 10 \\
\hline BC016 & 51 & 20.38 & IDC & 3 & 2 & 0 & 0 & $2 A$ & 0 & 1 & 3 & 30 \\
\hline BC017 & 64 & 15.45 & IDC & 2 & 2 & 3 & 0 & $3 C$ & 3 & 3 & 1 & 30 \\
\hline BC018 & 45 & 28.81 & IDC & 3 & 1 & 0 & 0 & $1 \mathrm{~A}$ & 3 & 3 & 3 & 20 \\
\hline BC019 & 60 & 27.32 & IDC & 1 & 2 & 0 & 0 & $2 \mathrm{~A}$ & 3 & 1 & 0 & 10 \\
\hline BC020 & 59 & 22.23 & IDC & 3 & 2 & 1 & 0 & $2 B$ & 0 & 0 & 3 & 40 \\
\hline BC021 & 60 & 37.90 & IDC & 3 & 2 & 0 & 0 & $2 \mathrm{~A}$ & 0 & 0 & 0 & 40 \\
\hline $\mathrm{BC} 022$ & 48 & 27.77 & IDC & 1 & 1 & 0 & 0 & $1 \mathrm{~A}$ & 3 & 3 & 1 & 5 \\
\hline $\mathrm{BC} 023$ & 44 & 18.34 & IDC & 2 & 3 & 3 & 0 & $3 C$ & 2 & 3 & 1 & 10 \\
\hline BCO24 & 52 & 12.36 & IDC & 1 & 1 & 0 & 0 & $1 \mathrm{~A}$ & 3 & 3 & 0 & 1 \\
\hline BC025 & 58 & 21.41 & IDC & 3 & 2 & 0 & 0 & $2 A$ & 3 & 0 & 3 & 40 \\
\hline
\end{tabular}

\footnotetext{
* Trx1; the blood level of Trx1 estimated by DxMe BC ELISA kit, HG; histological grade, T; the size and extent of the main tumor described in TNM staging system, $\mathrm{N}$; the number of nearby lymph nodes that have cancer described in TNM staging system, M; occurrence of metastasis described in TNM staging system, ER; test of estrogen receptor expression, PR; test of progesterone receptor expression, HER2, test of human epidermal growth factor receptor 2 expression, Ki67; antigen Ki-67 test to evaluate cell proliferation activity.
} 


\begin{tabular}{|c|c|c|c|c|c|c|c|c|c|c|c|c|}
\hline Patient No. & Age & $\operatorname{Trx1}(\mathrm{U} / \mathrm{ml})$ & Type & $\mathrm{HG}^{*}$ & $\mathrm{~T}^{*}$ & $\mathbf{N}^{*}$ & $\mathbf{M}^{*}$ & Stage & $\mathrm{ER}^{*}$ & $\mathrm{PR}^{*}$ & HER2* & Ki $67^{*}$ \\
\hline BC026 & 56 & 25.55 & IDC & 2 & 1 & 0 & 0 & $1 \mathrm{~A}$ & 2 & 0 & 1 & 10 \\
\hline $\mathrm{BC} 027$ & 55 & 17.64 & IDC & 2 & 2 & 2 & 0 & $3 \mathrm{~A}$ & 3 & 3 & 0 & 10 \\
\hline $\mathrm{BC} 028$ & 32 & 33.48 & IDC & 3 & 3 & 1 & 1 & 4 & 2 & 3 & 3 & 40 \\
\hline BC029 & 61 & 21.45 & ILC & 2 & 3 & 0 & 0 & $2 B$ & 3 & 3 & 2 & 5 \\
\hline BC030 & 41 & 27.01 & ILC & 2 & 3 & 0 & 0 & $2 B$ & 3 & 3 & 0 & 20 \\
\hline ВC031 & 48 & 29.24 & MC & 1 & 1 & 0 & 0 & $1 \mathrm{~A}$ & 3 & 0 & 3 & 4 \\
\hline BC032 & 35 & 27.53 & DCIS & 3 & 0 & 0 & 0 & 0 & 0 & 0 & 1 & 90 \\
\hline $\mathrm{BC033}$ & 65 & 31.46 & IDC & 1 & 1 & 0 & 0 & $1 \mathrm{~A}$ & 3 & 2 & 3 & 4 \\
\hline BC034 & 46 & 29.02 & IDC & 3 & 2 & 0 & 0 & $2 \mathrm{~A}$ & 2 & 2 & 1 & 25 \\
\hline BC035 & 55 & 25.68 & IDC & 1 & 2 & 0 & 0 & $2 \mathrm{~A}$ & 0 & 0 & 1 & 10 \\
\hline BC036 & 58 & 22.12 & IDC & 2 & 2 & 3 & 0 & $3 C$ & 3 & 2 & 1 & 1 \\
\hline BC037 & 65 & 15.48 & IDC & 1 & 1 & 0 & 0 & $1 \mathrm{~A}$ & 3 & 2 & 0 & 15 \\
\hline ВC038 & 50 & 16.97 & DCIS & 2 & 0 & 0 & 0 & 0 & 3 & 3 & 1 & 1 \\
\hline ВС039 & 54 & 20.71 & IDC & 2 & 2 & 0 & 0 & $2 \mathrm{~A}$ & 3 & 3 & 2 & 15 \\
\hline BC040 & 53 & 18.00 & IDC & 2 & 2 & 1 & 0 & $2 B$ & 3 & 2 & 1 & 10 \\
\hline BC041 & 49 & 20.67 & IDC & 3 & 2 & 0 & 0 & $2 \mathrm{~A}$ & 3 & 0 & 3 & 50 \\
\hline BC042 & 41 & 28.93 & IDC & 2 & 2 & 0 & 0 & $2 \mathrm{~A}$ & 3 & 2 & 1 & 25 \\
\hline $\mathrm{BC} 043$ & 43 & 32.46 & IDC & 2 & 2 & 1 & 0 & $2 B$ & 3 & 3 & 2 & 50 \\
\hline $\mathrm{BC} 044$ & 46 & 21.23 & IDC & 3 & 2 & 0 & 0 & $2 A$ & 3 & 3 & 3 & 25 \\
\hline $\mathrm{BC} 045$ & 48 & 54.03 & IDC & 3 & 2 & 2 & 0 & $3 A$ & 3 & 3 & 1 & 50 \\
\hline $\mathrm{BC} 046$ & 56 & 20.11 & IDC & 3 & 1 & 1 & 0 & $2 \mathrm{~A}$ & 1 & 0 & 0 & 60 \\
\hline $\mathrm{BC} 047$ & 57 & 9.03 & IDC & 3 & 1 & 0 & 0 & $1 \mathrm{~A}$ & 0 & 2 & 2 & 40 \\
\hline BC048 & 58 & 14.34 & IDC & 3 & 2 & 0 & 0 & $2 \mathrm{~A}$ & 1 & 0 & 3 & 40 \\
\hline BC049 & 30 & 16.90 & $\mathrm{MC}$ & 1 & 1 & 0 & 0 & $1 \mathrm{~A}$ & 3 & 3 & 0 & 5 \\
\hline BC050 & 57 & 22.16 & IDC & 2 & 1 & 1 & 0 & $2 \mathrm{~A}$ & 3 & 2 & 3 & 25 \\
\hline BC051 & 44 & 34.13 & IDC & 1 & 1 & 0 & 0 & $1 \mathrm{~A}$ & 3 & 3 & 0 & 5 \\
\hline
\end{tabular}

\footnotetext{
*Trx1; the blood level of Trx 1 estimated by DxMe BC ELISA kit, HG; histological grade, T; the size and extent of the main tumor described in TNM staging system, $\mathrm{N}$; the number of nearby lymph nodes that have cancer described in TNM staging system, M; occurrence of metastasis described in TNM staging system, ER; test of estrogen receptor expression, PR; test of progesterone receptor expression, HER2, test of human epidermal growth factor receptor 2 expression, Ki67; antigen Ki-67 test to evaluate cell proliferation activity.
} 


\begin{tabular}{|c|c|c|c|c|c|c|c|c|c|c|c|c|}
\hline Patient No. & Age & $\operatorname{Trx} 1(\mathrm{U} / \mathrm{ml})$ & Type & $\mathrm{HG}^{*}$ & $\mathrm{~T}^{*}$ & $\mathbf{N}^{*}$ & $\mathbf{M}^{*}$ & Stage & $\mathrm{ER}^{*}$ & $\mathrm{PR}^{*}$ & HER2* & Ki $67^{*}$ \\
\hline BC052 & 53 & 14.40 & IDC & 3 & 2 & 1 & 0 & $2 B$ & 3 & 3 & 1 & 25 \\
\hline BC053 & 48 & 23.43 & IDC & 2 & 1 & 0 & 0 & $1 \mathrm{~A}$ & 3 & 3 & 1 & 40 \\
\hline BC054 & 41 & 24.42 & IDC & 2 & 1 & 0 & 0 & $1 \mathrm{~A}$ & 3 & 3 & 0 & 40 \\
\hline BC055 & 49 & 34.44 & IDC & 2 & 1 & 0 & 0 & $1 \mathrm{~A}$ & 3 & 3 & 1 & 10 \\
\hline BC056 & 53 & 32.90 & IDC & 3 & 2 & 1 & 0 & $2 B$ & 0 & 0 & 3 & 30 \\
\hline BC057 & 50 & 18.20 & IDC & 2 & 2 & 1 & 0 & $2 B$ & 3 & 3 & 0 & 10 \\
\hline BC058 & 51 & 21.85 & IDC & 2 & 1 & 1 & 0 & $2 \mathrm{~A}$ & 3 & 3 & 1 & 1 \\
\hline BC059 & 43 & 17.99 & IDC & 2 & 2 & 0 & 0 & $2 \mathrm{~A}$ & 3 & 3 & 1 & 30 \\
\hline BC060 & 52 & 20.45 & IDC & 2 & 2 & 0 & 0 & $2 \mathrm{~A}$ & 0 & 0 & 3 & 25 \\
\hline BC061 & 56 & 24.45 & IDC & 2 & 3 & 2 & 1 & 4 & 3 & 3 & 1 & 2 \\
\hline BC062 & 57 & 30.26 & IDC & 3 & 2 & 2 & 0 & $3 \mathrm{~A}$ & 0 & 0 & 3 & 30 \\
\hline $\mathrm{BC} 063$ & 52 & 25.96 & IDC & 2 & 1 & 0 & 0 & $1 \mathrm{~A}$ & 3 & 3 & 0 & 40 \\
\hline BC064 & 40 & 22.26 & IDC & 2 & 2 & 1 & 0 & $2 B$ & 3 & 3 & 1 & 25 \\
\hline BC065 & 38 & 22.33 & IDC & 3 & 3 & 0 & 0 & $2 B$ & 0 & 0 & 1 & 70 \\
\hline BC066 & 46 & 16.32 & $\mathrm{MC}$ & 1 & 1 & 0 & 0 & $1 \mathrm{~A}$ & 3 & 3 & 1 & 10 \\
\hline BC067 & 41 & 14.14 & IDC & 3 & 2 & 2 & 0 & $3 A$ & 3 & 3 & 1 & 15 \\
\hline BC068 & 64 & 15.85 & IDC & 1 & 1 & 1 & 0 & $2 \mathrm{~A}$ & 3 & 0 & 1 & 1 \\
\hline BC069 & 48 & 21.53 & $\mathrm{MC}$ & 2 & 2 & 0 & 0 & $2 \mathrm{~A}$ & 3 & 3 & 1 & 10 \\
\hline BC070 & 51 & 18.72 & IDC & 2 & 1 & 0 & 0 & $1 \mathrm{~A}$ & 0 & 0 & 1 & 10 \\
\hline BC071 & 49 & 31.87 & IDC & 2 & 2 & 1 & 0 & $2 B$ & 0 & 0 & 0 & 60 \\
\hline BC072 & 47 & 21.19 & IDC & 2 & 1 & 0 & 0 & $1 \mathrm{~A}$ & 3 & 3 & 0 & 2 \\
\hline BC073 & 39 & 18.60 & IDC & 3 & 2 & 1 & 0 & $2 B$ & 0 & 0 & 1 & 50 \\
\hline BC074 & 48 & 18.86 & IDC & 2 & 2 & 1 & 0 & $2 B$ & 3 & 3 & 1 & 10 \\
\hline BC075 & 71 & 21.28 & IDC & 3 & 2 & 0 & 0 & $2 \mathrm{~A}$ & 3 & 3 & 3 & 25 \\
\hline BC076 & 46 & 25.26 & IDC & 1 & 1 & 0 & 0 & $1 \mathrm{~A}$ & 2 & 3 & 1 & 5 \\
\hline BC077 & 54 & 22.02 & IDC & 1 & 1 & 0 & 0 & $1 \mathrm{~A}$ & 3 & 3 & 0 & 1 \\
\hline
\end{tabular}

\footnotetext{
*Trx1; the blood level of Trx 1 estimated by DxMe BC ELISA kit, HG; histological grade, T; the size and extent of the main tumor described in TNM staging system, $\mathrm{N}$; the number of nearby lymph nodes that have cancer described in TNM staging system, M; occurrence of metastasis described in TNM staging system, ER; test of estrogen receptor expression, PR; test of progesterone receptor expression, HER2, test of human epidermal growth factor receptor 2 expression, Ki67; antigen Ki-67 test to evaluate cell proliferation activity.
} 


\begin{tabular}{|c|c|c|c|c|c|c|c|c|c|c|c|c|}
\hline Patient No. & Age & $\operatorname{Trx1}(\mathrm{U} / \mathrm{ml})$ & Type & $\mathrm{HG}^{*}$ & $\mathrm{~T}^{*}$ & $\mathbf{N}^{*}$ & $\mathbf{M}^{*}$ & Stage & $\mathrm{ER}^{*}$ & $\mathrm{PR}^{*}$ & HER2* & $\mathrm{Ki} 67^{*}$ \\
\hline BC078 & 55 & 27.19 & IDC & 3 & 2 & 0 & 0 & $2 \mathrm{~A}$ & 0 & 0 & 0 & 90 \\
\hline BC079 & 59 & 20.49 & IDC & 1 & 1 & 1 & 0 & $2 \mathrm{~A}$ & 3 & 3 & 1 & 10 \\
\hline BC080 & 57 & 23.01 & IDC & 2 & 1 & 0 & 0 & $1 \mathrm{~A}$ & 3 & 3 & 0 & 1 \\
\hline ВC081 & 32 & 12.70 & IDC & 2 & 2 & 0 & 0 & $2 \mathrm{~A}$ & 3 & 3 & 0 & 3 \\
\hline BC082 & 42 & 15.55 & TC & 1 & 1 & 0 & 0 & $1 \mathrm{~A}$ & 2 & 3 & 1 & 15 \\
\hline $\mathrm{BC} 083$ & 41 & 19.41 & IDC & 2 & 3 & 1 & 0 & $3 A$ & 2 & 2 & 0 & 2 \\
\hline BC084 & 49 & 18.05 & MC & 1 & 1 & 0 & 0 & $1 \mathrm{~A}$ & 3 & 3 & 0 & 2 \\
\hline BC085 & 49 & 16.81 & IDC & 3 & 2 & 1 & 0 & $2 B$ & 3 & 3 & 0 & 50 \\
\hline BC086 & 50 & 17.99 & IDC & 2 & 1 & 0 & 0 & $1 \mathrm{~A}$ & 3 & 3 & 1 & 25 \\
\hline BC087 & 44 & 14.53 & IDC & 2 & 1 & 0 & 0 & $1 \mathrm{~A}$ & 3 & 3 & 3 & 10 \\
\hline BC088 & 42 & 24.06 & IDC & 3 & 3 & 1 & 0 & $3 A$ & 0 & 0 & 3 & 40 \\
\hline BC089 & 52 & 11.71 & IDC & 2 & 1 & 0 & 0 & $1 \mathrm{~A}$ & 3 & 3 & 1 & 20 \\
\hline BC090 & 43 & 10.26 & IDC & 2 & 1 & 0 & 0 & $1 \mathrm{~A}$ & 3 & 3 & 1 & 15 \\
\hline ВC091 & 50 & 21.67 & IDC & 1 & 1 & 0 & 0 & $1 \mathrm{~A}$ & 3 & 3 & 1 & 5 \\
\hline BC092 & 72 & 18.49 & IDC & 3 & 2 & 0 & 0 & $2 \mathrm{~A}$ & 0 & 0 & 0 & 80 \\
\hline BC093 & 49 & 29.21 & IDC & 1 & 1 & 0 & 0 & $1 \mathrm{~A}$ & 3 & 3 & 0 & 15 \\
\hline BC094 & 36 & 26.65 & IDC & 3 & 1 & 0 & 0 & $1 \mathrm{~A}$ & 0 & 0 & 1 & 60 \\
\hline BC095 & 59 & 21.95 & IDC & 1 & 1 & 0 & 0 & $1 \mathrm{~A}$ & 3 & 0 & 1 & 5 \\
\hline BC096 & 45 & 16.05 & IDC & 3 & 2 & 0 & 0 & $2 A$ & 3 & 3 & 1 & 40 \\
\hline BC097 & 54 & 16.00 & IDC & 3 & 2 & 2 & 0 & $3 A$ & 0 & 0 & 3 & 60 \\
\hline BC098 & 47 & 14.92 & IDC & 1 & 1 & 0 & 0 & $1 \mathrm{~A}$ & 3 & 3 & 1 & 5 \\
\hline BC099 & 41 & 16.09 & IDC & 3 & 2 & 1 & 0 & $2 B$ & 2 & 3 & 1 & 50 \\
\hline BC100 & 49 & 19.35 & IDC & 2 & 3 & 3 & 0 & $3 C$ & 2 & 1 & 3 & 5 \\
\hline BC101 & 61 & 19.67 & IDC & 2 & 2 & 1 & 0 & $2 B$ & 0 & 0 & 1 & 10 \\
\hline BC102 & 46 & 21.91 & IDC & 1 & 1 & 0 & 0 & $1 \mathrm{~A}$ & 3 & 3 & 0 & 3 \\
\hline BC103 & 58 & 18.74 & IDC & 3 & 2 & 0 & 0 & $2 \mathrm{~A}$ & 0 & 0 & 3 & 50 \\
\hline
\end{tabular}

\footnotetext{
*Trx1; the blood level of Trx 1 estimated by DxMe BC ELISA kit, HG; histological grade, T; the size and extent of the main tumor described in TNM staging system, $\mathrm{N}$; the number of nearby lymph nodes that have cancer described in TNM staging system, M; occurrence of metastasis described in TNM staging system, ER; test of estrogen receptor expression, PR; test of progesterone receptor expression, HER2, test of human epidermal growth factor receptor 2 expression, Ki67; antigen Ki-67 test to evaluate cell proliferation activity.
} 


\begin{tabular}{|lllllllllllll|}
\hline Patient No. & Age & Trx1(U/ml) & Type & HG $^{*}$ & $\mathbf{T}^{*}$ & $\mathbf{N}^{*}$ & $\mathbf{M}^{*}$ & Stage & ER $^{*}$ & PR $^{*}$ & HER2 & Ki67 $^{*}$ \\
\hline BC104 & 43 & 21.48 & IDC & 2 & 2 & 0 & 0 & $2 A$ & 2 & 3 & 1 & 20 \\
\hline BC105 & 53 & 22.08 & ILC & 2 & 2 & 0 & 0 & $2 A$ & 3 & 1 & 3 & 2 \\
\hline BC106 & 55 & 19.15 & IDC & 2 & 2 & 2 & 0 & $3 A$ & 3 & 2 & 1 & 5 \\
\hline
\end{tabular}

*Trx1; the blood level of Trx1 estimated by DxMe BC ELISA kit, HG; histological grade, T; the size and extent of the main tumor described in TNM staging system, $\mathrm{N}$; the number of nearby lymph nodes that have cancer described in TNM staging system, M; occurrence of metastasis described in TNM staging system, ER; test of estrogen receptor expression, PR; test of progesterone receptor expression, HER2, test of human epidermal growth factor receptor 2 expression, Ki67; antigen Ki-67 test to evaluate cell proliferation activity.

\section{Ability of blood Trx1 level to identify breast cancer}

The Trx 1 level of sera estimated by the DxMe BC ELISA kit showed good separation between BC patients and normal healthy women (Fig. 1). Seven out of 114 normal healthy women (6.1\%) had a level over the cut-off value (14.13 Unit/ml), and six out of $106 \mathrm{BC}$ patients (5.7\%) were below the cut-off. However, most BC patients were well separated from most healthy subjects. According to the ROC curve analysis, the sensitivity and specificity were $94.3 \%$ and $94.7 \%$, respectively. The area under curve (AUC) was 0.985 when the pre-set cut-off value was $14.13 \mathrm{Unit} / \mathrm{ml}$. The mean value of the Trx 1 level from normal healthy women was $5.45 \pm 4.16 \mathrm{U} / \mathrm{ml}$ and that from BC patients was $21.96 \pm 6.79 \mathrm{U} / \mathrm{ml}$. The difference of mean values of serum Trx 1 level between normal healthy women and $\mathrm{BC}$ patients was big enough to distinguish $\mathrm{BC}$ from normal healthy cases. In contrast, a separate study using CA15-3, a test normally used in BC patients after treatment, with sera from BC patients and normal healthy women showed a sensitivity and specificity as $48.0 \%$ and $70.4 \%$, respectively (data not shown). When the Trx 1 tests were performed with Caucasian women bloods, the ability of the test to distinguish $\mathrm{BC}$ patients from normal healthy women was similar to that of this study as previously reported [24].

When the selectivity of the Trx 1 test for $\mathrm{BC}$ over group of other types of cancer was analyzed, it was clear that $\mathrm{BC}$ patients were well distinguished from both normal healthy women and patients with other types of cancers. While the mean level of Trx 1 of normal healthy women was $5.45 \pm 4.16 \mathrm{U} / \mathrm{ml}$ and of BC patients was $21.96 \pm 6.79$ $\mathrm{U} / \mathrm{ml}$, that of group of patients with other cancers was $2.70 \pm 2.01 \mathrm{U} / \mathrm{ml}$, which was close to the level of normal healthy women. Statistical analysis of Trx 1 levels indicated that there was a significant difference between the Trx 1 levels of BC patients and other types of cancer patients $(p<0.0001)$. This result indicated that the blood level of Trx1 was likely to identify BC specifically.

\section{Effect of age}

Breast cancer patients were grouped according to their age group, such as 30's, 40's, 50's, and 60 and over, and each serum was tested to quantitate Trx 1 and assess the effect of age (Fig. 2). The mean value of Trx 1 in sera from BC patients in their 30's was $22.60 \pm 7.14 \mathrm{U} / \mathrm{ml}$, and those of patients in their 40's, 50's, and 60's and over was $22.85 \pm 7.99,20.75 \pm 4.90$, and $22.44 \pm 7.53 \mathrm{U} / \mathrm{ml}$, respectively. Interestingly, the mean values did not differ much with age, whereas, generally the $\mathrm{BC}$ incidence rate went up as women got older. The average level of Trx 1 from $B C$ patients of all ages was $22.16 \pm 6.89 \mathrm{U} / \mathrm{ml}$. The mean age of all patients was close to 50 , which is in the 
age range showing the highest incidence of $\mathrm{BC}$ in Korea [27]. Similar results that showed no effect on Trx1 level of age and menstrual status of $\mathrm{BC}$ patients from Caucasian women were previously reported [24]. Breast cancer patients under and over the age of 50 showed similar levels of blood Trx1. Altogether, it is likely that there is no relationship between the level of Trx1 and patient age.

\section{Effect of breast cancer types and molecular subtypes}

The levels of Trx 1 were analyzed according to the types of BC, such as DCIS, IDC, ILC, IMPC, MC, and ITC to examine whether there was any correlation between BC type and Trx1 level (Fig. 3). Most patients had IDC $(n=$ 92), which had a mean level of Trx1 of $22.00 \pm 7.04 \mathrm{U} / \mathrm{ml}$. The levels were $24.63 \pm 3.91 \mathrm{U} / \mathrm{ml}$ for ILC $(n=5)$, $20.41 \pm 5.34 \mathrm{U} / \mathrm{ml}$ for MC $(n=5), 22.25 \pm 7.47 \mathrm{U} / \mathrm{ml}$ for DCIS $(n=2), 19.07 \mathrm{U} / \mathrm{ml}$ for IMPC $(n=1)$, and $15.55 \mathrm{U} / \mathrm{ml}$ for ITC $(n=1)$. All BC types showed levels ranging from $20.41 \pm 5.34 \mathrm{U} / \mathrm{ml}$ to $24.63 \pm 3.91 \mathrm{U} / \mathrm{ml}$. In spite of an insufficient number of sera from IMPC and ITC, as well as the relatively wide spread of the Trx 1 levels in IDC, the mean values of all types of $B C$ were higher than the cut-off value, indicating that there was no effect of $B C$ type on the level of Trx1for BC detection.

In addition, the effect of molecular subtypes of $B C$ was also investigated. Luminal $A$ and $B$ were known to be the most common subtypes of $B C$, which showed blood Trx1 levels of $20.18 \pm 5.92 \mathrm{U} / \mathrm{ml}$ and $23.31 \pm 7.85 \mathrm{U} / \mathrm{ml}$, respectively. Other subtypes, including TNBC and HER2-enriched, also presented similar values to luminal $A$ and B. The average level of Trx 1 was $22.52 \pm 6.44 \mathrm{U} / \mathrm{ml}$, which was much higher than the cut-off value. It indicated that there was no difference in Trx1 level in different molecular subtypes of BC.

\section{Effect of specific receptor expression profile}

As specific receptor expression shows specific pathological and genetical implications, and has indication for the treatment of $B C$, it is important to see whether the blood level of Trx 1 is influenced by the receptor expression patterns. Therefore, the blood level of Trx 1 was estimated from sera showing different expression profiles of ER, PR and HER2 (Fig. 4). Each receptor expression was assessed during biopsy. Almost $58 \%$ of BC patients had hormone receptor expression profiles of $\mathrm{ER}^{+}, \mathrm{PR}^{+}$, and HER2- (PPN). This group showed an average Trx 1 level of $20.91 \pm 7.30 \mathrm{U} / \mathrm{ml}$. The triple negative case (ER', $\left.\mathrm{PR}^{-}, \mathrm{HER}^{-}, \mathrm{NNN}\right)$ came second in number $(11.3 \%)$ and indicated a level of $24.45 \pm 5.84 \mathrm{U} / \mathrm{ml}$. The triple positive $\left(\mathrm{ER}^{+}, \mathrm{PR}^{+}, \mathrm{HER2}{ }^{+}, \mathrm{PPP}\right)$ consisted of $11.3 \%$ of the patients and showed an average level of Trx1 of $24.80 \pm 5.83 \mathrm{U} / \mathrm{ml}$. The number of patients with the $\mathrm{ER}^{-}$. $\mathrm{PR}^{+}, \mathrm{HER}^{+}$(NPP) expression profile was only one, so could not imply any scientific interpretation. Since the patients with certain specific receptor expression profiles were hard to recruit due to low incidence, the corresponding numbers of such patients in the study were low. However, their levels of Trx 1 were from 22.15 $\pm 6.14 .13 \mathrm{Unit} / \mathrm{ml}$ to $22.94 \pm 3.59 \mathrm{U} / \mathrm{ml}$ when one patient with NPP was excluded, which were much higher than the cut-off value. These results indicated that the expression pattern of ER, PR and HER2 did not influence the level of Trx 1 in sera of BC patients.

\section{Effect of breast cancer stage and grade}


As $\mathrm{BC}$ shows different anatomical and pathological characteristics according to its stage, the effect of $\mathrm{BC}$ stage on the blood level of Trx 1 was examined (Fig. 5). Almost half of the patients were at stage $2(47.2 \%)$, showing a Trx 1 level of $21.94 \pm 6.06 \mathrm{U} / \mathrm{ml}$. The second most common stage was $1(34.9 \%)$ with a Trx 1 level of $21.64 \pm 6.48$ $\mathrm{U} / \mathrm{ml}$, while stage $3(14.2 \%)$ followed, with a level of $21.86 \pm 9.76 \mathrm{U} / \mathrm{ml}$. Stages 0 and 4 were too small in number (1.9\% each), since it was difficult to recruit corresponding patients, and exhibited levels of $22.25 \pm 7.47$ and $28.97 \pm 6.39 \mathrm{U} / \mathrm{ml}$, respectively. When stage 1 and 2 were combined, they comprised more than $80 \%$ of the patients and averaged a blood level of Trx 1 of $21.79 \pm 6.27 \mathrm{U} / \mathrm{ml}$. All the blood levels of Trx 1 from different stages of $B C$ were higher than the cut-off value indicating that the blood level of Trx 1 was not affected by the stage of BC. It was interesting that all stages showed similar levels of Trx 1 , whereas we hypothesized that the level of Trx1 would increase as stage increases.

Almost half of the BC patients were in grade $2(n=51,48.1 \%)$, with a Trx 1 level of $21.19 \pm 5.87 \mathrm{U} / \mathrm{ml}$. The levels of Trx 1 of grades 1 and 3 were also higher than the cut-off value. More than two third of the patients were in grades 2 and 3 , and a large portion of them were likely to have relatively fast-growing and metastatic cancer cells. Altogether, the blood level of Trx1 in BC was not affected by cancer stage or grade.

\section{Comparison analysis with mammography}

As mammography has long been regarded as the gold standard for the screening of $\mathrm{BC}$, it was necessary to see how well the level of Trx 1 corresponded to the matching mammogram. The mammograms and Trx 1 levels of a total of 103 out of 106 participating BC patients and 42 out of 114 normal healthy women were compared (Fig. 6, and Table 3). 
Table 3

Comparison study with mammography and Trx 1 level

\begin{tabular}{|c|c|c|c|c|c|c|}
\hline $\begin{array}{l}\text { Mammography } \\
\text { BI-RADS }\end{array}$ & $\begin{array}{l}\text { Confirmed } \\
\text { BC } \\
\text { patients }\end{array}$ & $\begin{array}{l}\text { Normal } \\
\text { women }\end{array}$ & Indicator & Mammography & $\begin{array}{l}\text { Trx1 } \\
\text { level }\end{array}$ & $\begin{array}{l}\text { Mammography } \\
\text { and Trx1 level }\end{array}$ \\
\hline Categories 4-5 & 71 & 0 & Sensitivity(\%) & 68.93 & 94.17 & 96.12 \\
\hline Categories $0-3$ & 32 & 42 & Specificity(\%) & 100.00 & 92.86 & 100.00 \\
\hline Total & 103 & 42 & $\operatorname{PPV}(\%)$ & 100.00 & 97.00 & 100.00 \\
\hline Trx1 level & & & $N P V(\%)$ & 56.76 & 86.67 & 91.30 \\
\hline $\begin{array}{l}\geq 14.13 \\
\text { Unit/ml }\end{array}$ & 97 & 3 & & & & \\
\hline$<14.13$ Unit/ml & 6 & 39 & & & & \\
\hline Total & 103 & 42 & & & & \\
\hline \multicolumn{7}{|c|}{ Mammography and Trx 1 level ${ }^{2}$} \\
\hline Positive & 99 & 0 & & & & \\
\hline Negative & 4 & 42 & & & & \\
\hline Total & 103 & 42 & & & & \\
\hline
\end{tabular}

${ }^{1}$ Participating BC patients were previously confirmed to have BC by biopsy.

2 In combined test with mammography and Trx 1 level, it was regarded as positive when the test results showed the BI-RADS category 4 or over or the Trx1 level was higher than the cut-off value $(14.13 \mathrm{Unit} / \mathrm{ml})$. Similarly, it was regarded as negative when either result was in BI-RADS categories 1-3 or lower Trx1 level than the cut-off value. PPV, positive predictive value; NPV, negative predictive value.

The mammograms of BC patients were judged and classified according to the BI-RADS scoring system. Results showed that 71 out of 103 biopsy-confirmed BC patients were classified into BI-RADS categories $4(n=52)$ and $5(n=19)$ and the remaining 32 were classified into categories $0(n=29), 1(n=1), 2(n=1)$ and $3(n=1)$. Therefore, $31.1 \%$ of biopsy-confirmed BC patients were classified into BI-RADS category 0 to 3 , and most of them were in category $0(n=29,28.2 \%)$. All normal healthy subjects were classified as BI-RADS category 3 and under, and most of them were in category $1(n=32,76.2 \%)$. If BI-RADS category 4 and over indicates true positive diagnosis of $\mathrm{BC}$, only $68.9 \%$ of the $\mathrm{BC}$ patients were correctly identified by mammography, compared to high accuracy in identifying normal healthy women. When the blood Trx 1 level was analyzed, 97 out of 103 biopsy confirmed BC patients showed values higher than the cut-off value (14.13 Unit/ml), indicating true positive diagnosis of BC. For the normal healthy women, 39 out of 42 showed a Trx 1 level below the cut-off value, implying true negative diagnosis of BC. Next, the sensitivity and specificity of mammography and the Trx1 test was estimated by ROC curve analysis. Mammography showed a sensitivity and specificity of $68.9 \%$ and $100 \%$, respectively. Those of the Trx 1 test were $94.17 \%$ and $92.86 \%$, respectively. Interestingly, when mammography and the Trx 1 test were combined, the sensitivity and specificity rose to an almost perfect $96.12 \%$ and $100.0 \%$, respectively. When mammography and Trx 1 level were analyzed separately, mammography exhibited low negative predictive value (NPV, 56.76\%) and high positive predictive value (PPV, 
100\%). On the other hand, the Trx1 level revealed high values both for both NPV (86.67\%) and PPV (97.00\%). When these two tests were combined, PPV reached $100 \%$ and NPV reached $91.30 \%$. It implied that combined examination with mammography and the Trx 1 test could create a synergy and achieve the highest diagnostic performance.

\section{Discussion}

Currently used tumor biomarkers related to BC diagnosis and management are CA15-3, CA27.29, CEA, and CA125 [21-23]. They can be used to monitor the progression of cancer, evaluate the outcome of specific treatment, or monitor a recurrence. However, tumor biomarker tests have their own limitations; the level change of the biomarker is not always caused by cancer, and healthy subjects quite often also show increased levels of certain biomarkers. Therefore, tumor biomarker tests cannot be used alone to evaluate or manage BC. Despite the clinical benefits of using tumor biomarker tests to assist in the correct reading or compensate for technical limits of imaging examinations, it is difficult to find ones with sufficiently high sensitivity and specificity.

In mammalian cells, Trx1 is involved in the regulation of reactive oxygen species (ROS) levels [28, 29]. As it plays a role in the regulation of cellular redox homeostasis, Trx1 has multiple functions in the cell. Therefore, Trx1 is an important entity that is potentially related to the onset of many diseases, including cancer, inflammation diseases, heart failure, and so on. Trx 1 has been known to play an important role in regulating cancer cell growth by modulating the DNA binding activity of transcription factors [29-33]. It has been reported that the blood level of Trx1 was specifically higher in breast cancer compared with a few other cancer types [24]. Even though Trx1 is likely expressed in a few different types of cancer as well as in normal healthy women, the largest difference in the Trx1 level between sera from normal and cancer subjects was shown in BC.

Therefore, if this Trx1 level difference could be distinguished from the difference engendered by normal healthy women and other types of cancers, it would be possible to detect BC from the blood. This was the main basis of BC-specific detection of Trx1 in the present study.

When the cut-off value was set at 14.13 Unit/ml of Trx1, the sensitivity and specificity for BC detection was $94.3 \%$ and $94.7 \%$, respectively with an AUC of 0.985 . These values were relatively high compared to previously reported values for other protein cancer biomarker tests, which ranged from 60-90\% [21-23]. The average value of Trx1 level in normal sera was $5.45 \pm 4.16 \mathrm{U} / \mathrm{ml}$ and that of sera from BC patients was $21.96 \pm 6.79 \mathrm{U} / \mathrm{ml}$, which was a large enough difference to identify BC subjects from normal healthy ones. The Trx1 level of patients with other types of cancer was close to that of normal healthy subjects, indicating that the blood Trx 1 level could discern BC from other types of cancer. Even though the sample numbers of certain other types of cancer were insufficient, it still provides important clues about what could be expected from those other types of cancer. It should be acknowledged that there is a pile of reports showing increased expression of Trx 1 in various types of cancer [34-39]. However, most of the studies were carried out in cancer cells or tissue not in blood, and focused on the gene expression level of Trx1. Since the physiological environment of blood is quite different from that of cells or tissue, it is necessary to scrutinize the level of Trx 1 protein in blood from large numbers of patients with different types of cancer. The effect of many chronic inflammation diseases was also tested, and it did not show any meaningful effect on the ability of Trx 1 level to identify BC patients (data not shown).

Breast cancer patients were identified by the level of Trx 1 in sera, and this was not influenced by age. In particular, BC patients in their late 40 s to early 50 s, the age group with the highest BC incidence in Korea, were 
differentiated from normal subjects. Breast cancer patients in other age groups were also equally well identified by Trx 1 level. It has also been reported that there is no influence of the menstrual status of Caucasian women on Trx1 level [24]. It was interesting that the level of Trx1 did not significantly change with subject age. Since it has been commonly accepted that the incidence rate of BC gets higher in older age [2, 3], it could be expected that Trx1 level would follow suit. However, no significant difference was observed.

Breast cancer has complicated classifications and shows its own pathological characteristics for diagnosis and treatment as well $[16,17]$. IDC, which comprised the largest number of BC patients in the study and in the Korea breast cancer incidence database, had an average Trx1 level of 22.00 $27.04 \mathrm{U} / \mathrm{ml}$. ILC and MC also showed similar values, indicating that blood Trx 1 level can detect $B C$ regardless of $B C$ type. The number of cases of DCIS, IMC and ITC were low, since the incidence rate of each was low and, thus, it was difficult to collect blood from these types of BC patients. All DCIS blood showed a high value of Trx1, which implies the potential of the Trx1 level for the very early detection of BC. It will be interesting to conduct a study with a large numbers of DCIS blood samples to check whether this is the case. If the level of Trx 1 can detect BC even in large number of DCIS cases, it will be useful for the early detection of BC. Despite different pathological characteristics of different types of BC, there was no significant difference between Trx1 levels in any type. This strongly indicates that the blood level of Trx1 is a good means to detect BC.

As it was likely that the blood level of Trx 1 was suitable to detect $\mathrm{BC}$, it was interesting to check whether it could differentiate the stage of BC. The level of Trx1 in blood was not significantly changed by the stage of BC. It showed higher values than the cut-off value no matter what the stage of $\mathrm{BC}$ was, and thus, it indicated that Trx 1 level was likely to detect $B C$ regardless of $B C$ stage. It was promising to see high accuracy to identify patients from stage 1 as well as other stages. This result means that the blood level of Trx 1 could be an alternative modality for the early detection of BC.

The sensitivity (68.9\%) and specificity (100.0\%) of mammography of BC in this study is typical when compared with other recent reports on mammography $[11,13]$. However, the fact that more than one third of biopsy confirmed BC patients in this study were judged as an inconclusive (BI-RADS category 0 ) is concerning. The BIRADS category 0 means that the final assessment of the mammogram is likely to be held off until additional tests and images are available. It may cost money, time, and anxiety. It is interesting that the Trx 1 test was generally superior to mammography in this study, and that the combined test with mammography and Trx 1 showed the highest accuracy to detect BC. Since biomarker tests cannot be used alone to diagnose a certain cancer or disease, and mammography has not achieved desirable performance for BC screening, the combined test will yield complementary effects that mitigate the weakness of each test and provide the highest accuracy for $\mathrm{BC}$ detection.

Although there is no doubt of the need to carry on a larger population study with different types of cancer, it is likely that the level of Trx1 can detect BC specifically. In addition, Trx1 level was not affected by different characteristics of BC. This indicates that the blood level of Trx1 has potential as a biomarker for BC. Although there have been many reports regarding the role or mode of action of Trx1 in cancer, it has not been completely elucidated [40-44]. When cancer cells grow, the microenvironment of cancer cells is in a hypoxic state that favors ROS generation, resulting in higher oxidative stress. Cancer cells are inclined to protect themselves from oxidative damage via maintaining their redox status to survive and metastasize to distant organs. In this condition, Trx 1 modulates redox signaling pathways via thiol-disulfide exchange with redox-responsive proteins, 
such as the transcription factors Ref-1 and NF-KB, MAP3K5/ASK1, and Trx1 interacting protein. This kind of signaling causes modulation of cell kinetics such as activation of proliferation, inhibition of apoptosis, and facilitation of metastasis of cancer cells. However, most previous studies have been done with cancer cell lines or cancer tissue that had an environment very different to the blood system, especially in terms of redox status. It has been reported that the mRNA level of the Trx1 gene is correlated with the proceeding of BC stages, whereas the protein level of Trx1 in blood is likely kept constant [24]. It can be assumed that Trx1 is also likely involved in other cell kinetics, such as the initiation or switch mechanism of BC. It requires a well-designed elaborate study to prove this kind of speculation.

It has been long accepted that mammography contributes to the early detection of $\mathrm{BC}$, thus lowering its mortality. Nevertheless, it has some well-known limitations, such as lack of mobility, radiation exposure, uncomfortable personal experience, and cost in certain countries. In addition, satisfactory sensitivity and specificity of mammography, especially for women with dense breasts, has not been reached. Therefore, it would be greatly beneficial to have a simple, economic, and complementary means to detect BC with high accuracy in relatively early stages. When the Trx 1 level of patients was analyzed along with readings of mammograms from the same patients, the sensitivity and specificity of coupled tests went up to $99.25 \%$ and $100.00 \%$, respectively. Interestingly, this benefit was more obvious in the case of dense breasts (manuscript in preparation). Therefore, it seems that the level of Trx1 in blood could be a promising modality to detect BC as a complement to current diagnostic methods.

\section{Conclusions}

As has long been asked for, the level of Trx 1 in serum is likely to be a promising candidate for a better way to detect $\mathrm{BC}$ in concert with current mammography. It can differentiate $\mathrm{BC}$ patients from normal healthy women with high sensitivity and specificity, regardless of age or pathological and molecular BC types. It also differentiates $\mathrm{BC}$ from other types of cancer. When it was used together with mammography, it showed almost perfect accuracy to identify BC. Even though it is necessary to study with a much larger population of BC and other types of cancer, it is likely that the level of blood Trx 1 can be a novel means to detect BC.

\section{Abbreviations}

BC, breast cancer; Trx1, thioredoxin 1; ER, estrogen receptor; PR, progesterone receptor; HER2, human epidermal growth factor receptor 2; CA15-3, cancer antigen 15 - 3; CEA, carcinoembryonic antigen; CA27.29, cancer antigen 27.29, CA125, cancer antigen 125; ELISA, enzyme linked immunosorbent assay; IDC, invasive ductal carcinoma; DCIS, ductal carcinoma in-situ; ILC, invasive lobular carcinoma; IMC, invasive micropapillary carcinoma; $\mathrm{MC}$, mucinous carcinoma; ITC, invasive tubular carcinoma; $\mathrm{ROC}$, receiver operating characteristic; AUC, area under curve; ROS, reactive oxygen species; ER, estrogen receptor; PR, progesterone receptor; HER2, human epidermal growth factor receptor 2; TNBC, triple negative breast cancer

\section{Declarations}

\section{Authors' contributions}


YJL carried out collection of clinical data, participated in collection and preparation of biological samples, immunohistochemistry, and receptor expression, and contributed to the preparation of tables and figures. YK participated in the measurement of Trx 1 level, post-processing of collected biological samples, analysis of data, and the preparation of tables and figures. BBC contributed to recruit patients, judgment and analysis of mammograms, comparison analysis of mammograms and Trx1 levels. JRK carried out patient recruitment, analysis of clinical information, and participated in receptor expression profile analysis. HMK conducted patient recruitment, collection of biological samples, analysis of cancer type and stage, preparation of figures. KHS participated in study design, data analysis, and preparation of manuscript. JSL contributed to design of the study, recruit patients, collection of biological samples, analysis of data, and preparation of manuscript. KHS and JSL contributed equally as a correspondence. Special thanks to Michael Moses for the proof reading of the English of the manuscript.

\section{Funding}

This study (N0002386) was supported by the Take-off Platform (TOP) grant of commercialization-linked R\&BD from KIAT, funded by the Ministry of Trade, Industry and Energy of Korea (MOTIE).

\section{Availability of data and materials}

The datasets used and/or analyzed during the current study are available from the corresponding author on reasonable request.

\section{Ethics approved and consent to participate}

The study was approved by the institutional ethics committee of the Chungnam National University Hospital. All patients provided informed consents before donating blood.

\section{Consent for publication}

Not applicable

\section{Competing interests}

The authors declare that they have no competing interests.

\section{Author details}

Youn Ju Lee, Department of Surgery, Chungnam National University Sejong Hospital, Sejong, Department of Surgery and Research Institute for Medicinal Sciences, Chungnam National University School of Medicine, Daejeon, Korea. jaennejunya@cnuh.co.kr

Young Kim, E\&S Healthcare, Daejeon, Korea, Department of Surgery, College of Medicine, Yonsei University, 262 Seongsan-no, Seodaemun-gu, Seoul, Korea. youngkim@ens-h.com,

Bo Bae Choi, Department of Radiology, Chungnam National University Hospital, Daejeon, Korea. med20@cnuh.co.kr 
Je Ryong Kim, Department of Surgery, Chungnam National University Hospital, Department of Surgery and Research Institute for Medicinal Sciences, Chungnam National University School of Medicine, Daejeon, Korea. kimjr@cnu.ac.kr

Hye Mi Ko, Department of Surgery, Chungnam National University Hospital, Department of Surgery and Research Institute for Medicinal Sciences, Chungnam National University School of Medicine, Daejeon, Korea. camomill@cnuh.co.kr

Kyoung Hoon Suh, E\&S Healthcare, Daejeon, Korea. one@ens-h.com, Department of Life Science and Technology, Pai Chai University, Daejeon, Korea. khsuh@pcu.ac.kr

Jin Sun Lee, Department of Surgery, Chungnam National University Hospital, Department of Surgery and Research Institute for Medicinal Sciences, Chungnam National University School of Medicine, Daejeon, Korea. leejin0520@cnuh.co.kr

\section{References}

1. Bray F, Ferlay J, Soerjomataram I, Siegel RL, Torre LA. Global cancer statistics 2018: GLOBOCAN estimates of incidence and mortality worldwide for 36 cancers in 185 countries. CA Cancer J Clin. 2018;68:394.

2. Ginsburg O, Bray F, Coleman MP, Vanderpuye V, Eniu A, Kotha R, et al. The global burden of women's cancers: a grand challenge in global health. Lancet. 2017;389:847.

3. Torre LA, Siegel RL, Ward EM, Jemal A. Global cancer incidence and mortality rates and trends - an update. Cancer Epidemiol Biomarkers Prev. 2016;25:16.

4. Leong SPL, Shen ZZ, Liu TJ, Agarwal G, Tajima T, Paik NS, et al. Is breast cancer the same disease in Asian and western countries? World J Surg. 2011;34:2308.

5. Agarwal G, Pradeep PV, Aggarwal V, Yip CH, Cheung PSY. Spectrum of breast cancer in Asian women. World J Surg. 2007;31:1031.

6. Allemani C, Weir HK, Carreira H, Harewood R, Spika D, Wang XS, et al. Global surveillance of cancer survival 1995-2009: analysis of individual data for 25,676,887 patients from 279 population-based registries in 67 countries (CONCORD-2). Lancet. 2015;385:977.

7. Wendie A. Benefits of screening mammography. JAMA. 2010;303:168.

8. World Health Organization. WHO position paper on mammography screening. WHO; 2014.

9. Wald N, Chamberlain J, Hackshaw A. Report of the European Society of Mastology: Breast cancer screening evaluation committee. Breast. 1993;2:209.

10. Swedish Cancer Society and the Swedish National Board of Health and Welfare. Breast-cancer screening with mammography in women aged 40-49 years. Int J Cancer. 1996;68:693.

11. Jacobson KK, O'Meara ES, Key D, Buist DSM, Kerilkowske K, Vejborg I, et al. Comparing sensitivity and specificity of screening mammography in the United States and Denmark. Intl J Cancer. 2015;137:2158.

12. von Euler-Chelrin M, Lillholm M, Vejborg I, Nielsen M, Lynge E. Sensitivity of screening mammography by density and texture: a cohort study from a population based program in Denmark. Cancer Res.

2019;21:111.

Page 19/27 
13. Pisano ED, Hendrick RE, Yaffe MJ, Baum JK, Acharyya S, Cormack JB, et al. Diagnostic accuracy of digital versus film mammography: exploratory analysis of selected population subgroups in DMIST. Radiology. 2008;246:376.

14. Cohen JD, Li L, Wang Y, Thoburn C, Afsari B, Danilova L, et al. Detection and localization of surgically resectable cancers with a multi-analytic blood test. Science. 2018;359:926.

15. Liu MC, Oxnard GR, Klein EA, Swanton C, Seiden MV. Sensitive and specific multi-cancer detection and localization using methylation signatures in cell-free DNA. Annal Oncol. 2020;31:745.

16. National Comprehensive Cancer Network. NCCN Clinical Practice Guidelines in Oncology: Breast Cancer. Nccn. Org. 2018. http://www.nccn.org/professionals/physician_gls/pdf/breast.pdf.

17. Senkus E, Kyriakides S, Ohono S, Poortmans P, Rutgers E, Zackrisson S, et al. Primary breast cancer: ESMO Clinical Practice Guidelines for diagnosis, treatment, and follow-up. Ann. Oncol. 2015;26(Suppl. 5):v8.

18. Kuchenbaecker KB, Hopper JL, Barnes DR, Phillio KA, Mooij TM, Roos-Blom MJ, et al. Risks of breast, ovarian, and contralateral breast cancer for BRCA1 and BRCA2 mutation carriers. JAMA. 2017;317:2402.

19. Cardoso F, van't Veer LJ, Bogaerts J, Slaets L, Viale G, Delaloge S, et al. 70-Gene signature as an aid to treatment decision in early-stage breast cancer. N Engl J Med. 2016;375:717.

20. Sparano JA, Gray RJ, Makower DF, Pritchard KI, Albain KS, Hayes DF, et al. Prospective validation of a 21gene expression assay in breast cancer. N Engl J Med. 2015;373:2005.

21. Ahmed M. Kabel. Tumor markers of breast cancer: New perspectives. J Oncol Sci. 2017;3:5.

22. Pons-Anicet DM, Krebs BP, Mira R, Namer M. Value of CA15-3 in the follow-up of breast cancer patients. Br J Cancer. 1987;55:567.

23. Yang Y, Zhang H, Zhang M, Meng Q, Cai L, Zhang Q. Elevation of serum CEA levels during antitumor therapy predict poor therapeutic response in advanced BC patients. Oncol Lett. 2017;14:7549.

24. Cha MK, Suh KH, Kim IH. Overexpression of peroxiredoxin I and thioredoxin I in human breast carcinoma. J Exp Clin Cancer Res. 2009;28:93.

25. Park BJ, Cha MK, Kim IH. Thioredoxin 1 as a serum marker for breast cancer and its use in combination with CEA or AC15-3 for improving sensitivity of breast cancer diagnosis. BMC Res Notes. 2014;7:7.

26. Nakamura HA, Valen JV, Padilla CA, Björnstedt M, Holmgren A. Measurement of plasma glutaredoxin and thioredoxin in healthy volunteers and during open-heart surgery. Free Radical Biol Med. 1998;24:1176.

27. Kang SY, Kim YS, Kim Z, Kim HY, Kim HJ, Park S. Breast cancer statistics in Korea in 2017: data from a breast cancer registry. J Breast Cancer. 2020;23:115.

28. Ohira A, Honda O, Gauntt CD, Yamamoto M, Hori K, Mastutani H, et al. Oxidative stress induced adult $T$ cell leukemias derived factor/thioredoxin in the rat retina. Lab Invest. 1994;70:279.

29. Sasada T, Iwata S, Sato N, Kitaoka Y, Hirota K, Nakamura K, et al. Redox control of resistance to cisdiamminedichloroplatinum (III) (CDDP): Protective effect of human thioredoxin against CDDP-induced cytotoxicity. J Clin Invest. 1996;97:2268.

30. Schenk H, Klein M, Erdbrügger W, Dröge W, Schulze-Osthoff K. Distinct effects of thioredoxin and antioxidants on the activation of transcription factors NF-KB and AP-1. Proc. Natl. Acad. Sci. USA. 1994;91:1672. 
31. Hayashi S, Hajiro-Nakanishi K, Makino Y, Eguchi H, Yodori J, et al. Functional modulation of estrogen receptor by redox state with reference to thioredoxin as mediator. Nucleic Acids Res. 1997;25:4035.

32. Ueno M, Masutani H, Arai RJ, Yamaguchi A, Hirota K, Sakai T, et al. Thioredoxin-dependent redox regulation of p53-mediated p21 activation. J Bio Chem. 1999;274:35809.

33. Day AM, Brown JD, Taylor SR, Rand JD, Morgan BA, Veal EA. Inactivation of a peroxiredoxin by hydrogen peroxide is critical for thioredoxin-mediated repair of oxidized proteins and cell survival. Mol Cell. 2012;45:398.

34. Zhu H, Tao X, Shou L, Sheng B, Zhu X. Expression of thioredoxin-1 and peroxiredoxins in squamous cervical carcinoma and its predictive role in NACT. BMC Cancer. 2019;19:865.

35. Wangpaichitr M, Theodoropoulos G, Wu C, You M, Feun LG, Kuo MT, et al. The relationship of thioredoxin 1 and cisplatin resistance: Its impact on ROS and oxidative metabolism in lung cancer cells. Mol Cancer Ther. 2012;11:604.

36. Lin F, Zhang P, Zuo Z, Wang F, Bi R, Shang W, et al. Thioredoxin-1 promotes colorectal cnacer invasion and metastasis through crosstalk with S100P. Cancer Lett. 2017;401:1.

37. Raffel J, Bhattacharyya AK, Gallegos A, Cui H, Einspahr JG, Albers DS, et al. Increased expression of thioredoxin-1 in human colorectal cancer is associated with decreased patient survival. J Lab Clin Med. 2003;142:46.

38. Shang W, Xie Z, Lu F, Fang D, Tang T, Bi R, et al. Incrreased thioredoxin-1 expression promotes cancer progression and predicts poor prognosis in patients with gastric cancer. Oxidative Med Cell Longevity. 2019. doi:10.1155/2019/9291683.

39. Lincoln AT, Al-Yatama F, Mohammed FMA, Al-Banaw AG, Al-Bader M, Burge M, et al. Thioredoxin and thioredoxin reductase expression in thyroid cancer depends on tumour aggressiveness. Anticancer Res. 2010;30:767.

40. Harris IC, Treolar AE, Inoue S, Sasaki M, Gorrini C, Kim JL, et al. Glutathione and thioredoxin antioxidant pathways synergize to drive cancer initiation and progression. Cancer Cell. 2015;27:211.

41. Mahmood D, Abderrazak A, Hadri KE, Simmet T. The thioredoxin system as a therapeutic target in human health and disease. Antioxid Redox Signal. 2013;19:1266.

42. Liu Y, Zhao Y, Wei Z, Tao L, Sheng X, Wang S, et al. Targeting thioredoxin system with an organosulfur compound, diallyl trisulfide (DATS), attenuate progression and metastasis of triple-negative breast cancer (TNBC). Cell Physiol Biochem. 2018;50:1945.

43. Monteiro HP, Ogata FT, Stern A. Thioredoxin promotes survival signaling events under nitrosative/oxidative stress associated with cancer development. Biomed J. 2017;40:189.

44. Bhatia M, McGrath KL, Trapani GD, Charoentong P, Shah F, King MM, et al. The thioredoxin system in breast cancer cell invasion and migration. Red Biol. 2016;8:68.

\section{Figures}


A

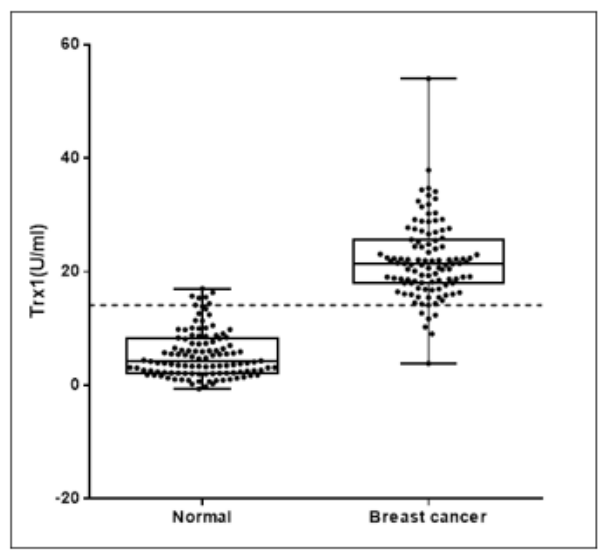

B

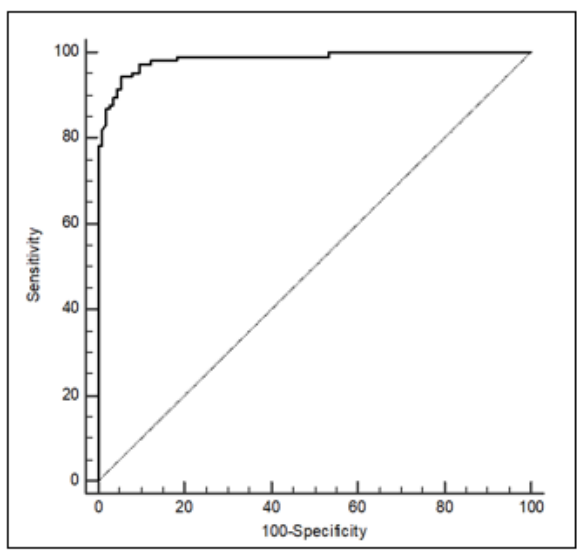

C

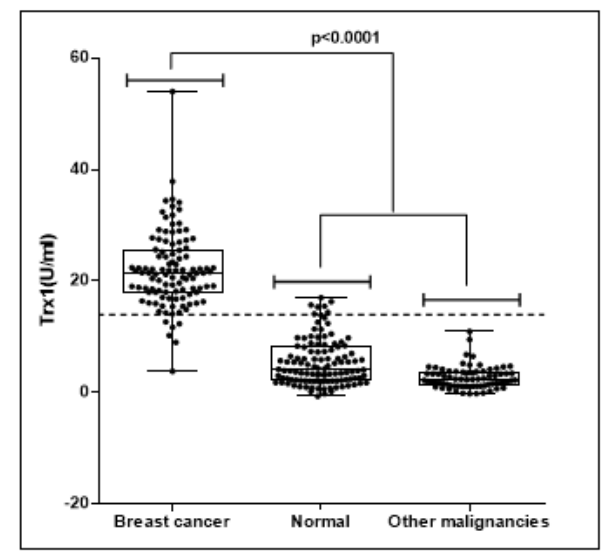

\section{Figure 1}

Higher blood level of Trx1 in BC patients compared with normal healthy women and other types of cancer patients. (A) Separation of BC patients from normal healthy women by blood level of Trx1. The dotted line indicates the cut-off value of Trx1 level (14.13 Unit/ml). (B) ROC curve analysis to determine the ability of blood Trx 1 level to differentiate BC from normal healthy women. The sensitivity and specificity were $94.3 \%$ and $94.7 \%$, respectively, with an AUC of 0.985 . (C) Selectivity of BC by the level of Trx 1 compared to other types of cancer including cervical, lung, colorectal, gastric, and thyroid cancer. 


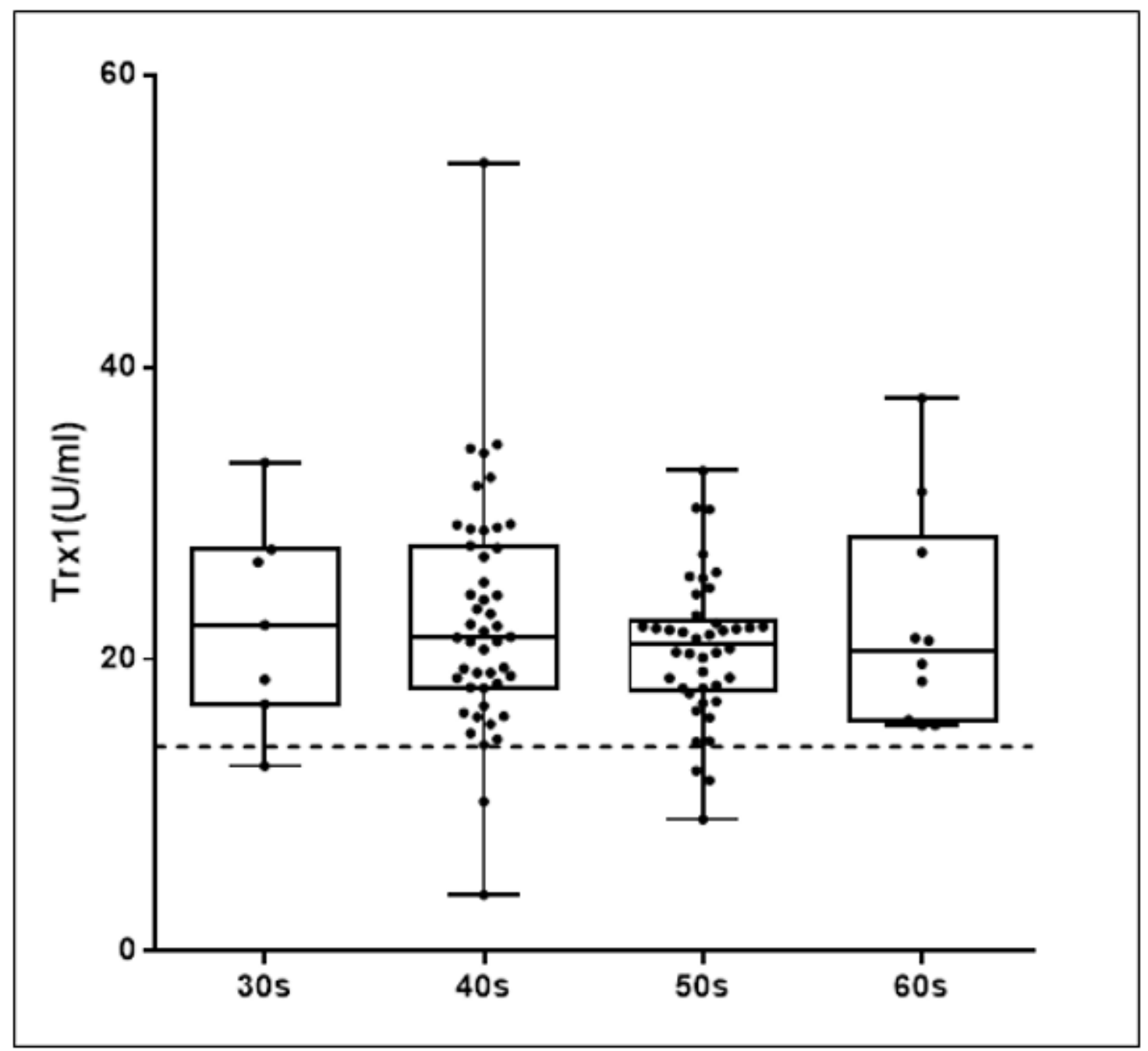

Figure 2

The effect of age on the level of blood Trx1 Breast cancer patients were divided into age groups of the 30s, 40s, $50 \mathrm{~s}$, and 60 and over, and their blood levels of Trx 1 were compared. The dotted line indicates the cut-off value of Trx1 level (14.13 Unit/ml). 
A

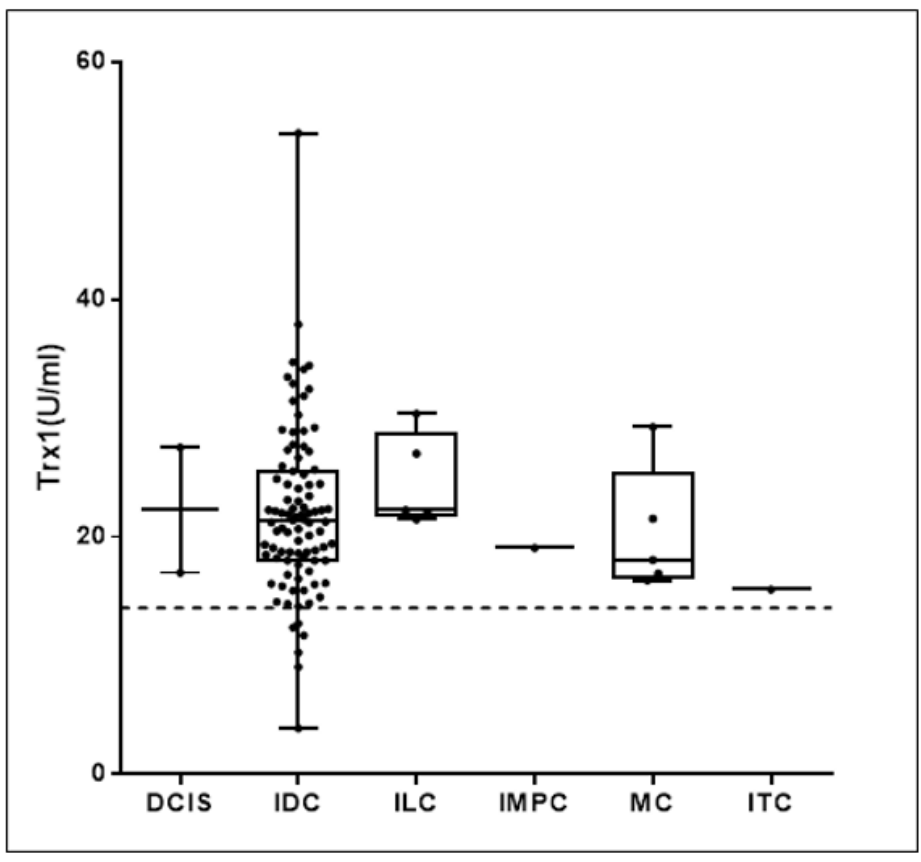

B

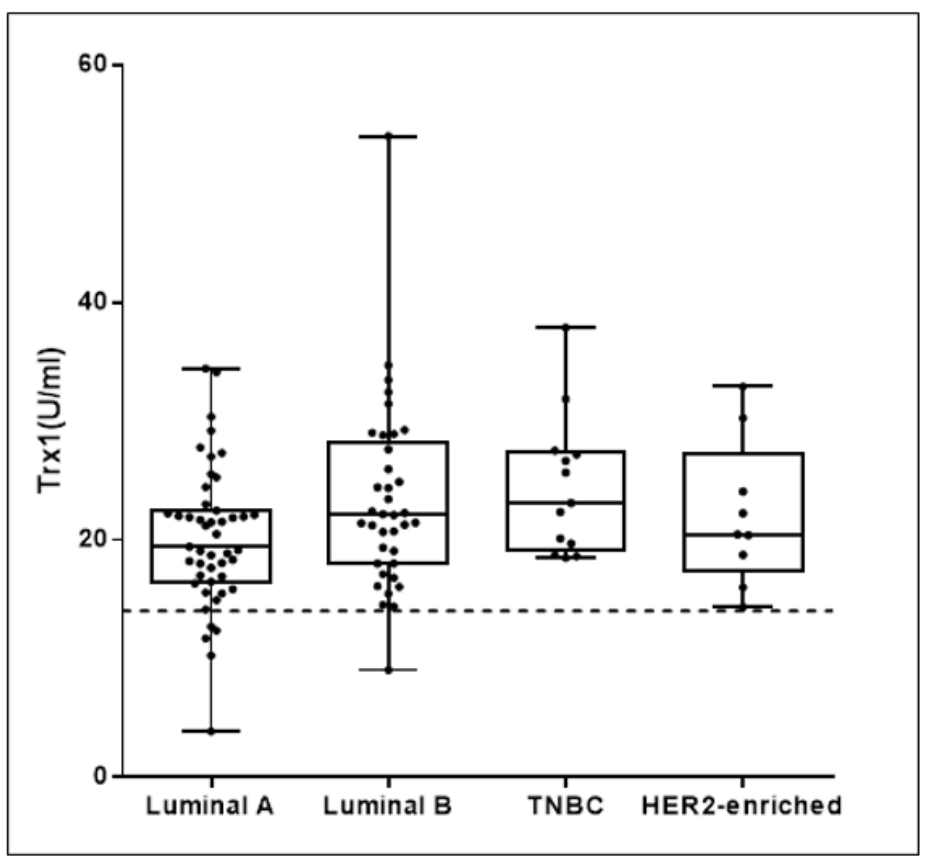

\section{Figure 3}

The effect of breast cancer types on the blood level of Trx1 (A) The effect of pathological types of breast cancer. DCIS, ductal carcinoma in-situ; IDC, invasive ductal carcinoma; ILC, invasive lobular carcinoma; IMPC, invasive micropapillary carcinoma; MC, mucinous carcinoma; ITC, invasive tubular carcinoma. (B) The effect of molecular subtypes of breast cancer on the level of blood Trx1. TNBC, triple negative breast cancer. The dotted line indicates the cut-off value of Trx1 level (14.13 Unit/ml). 


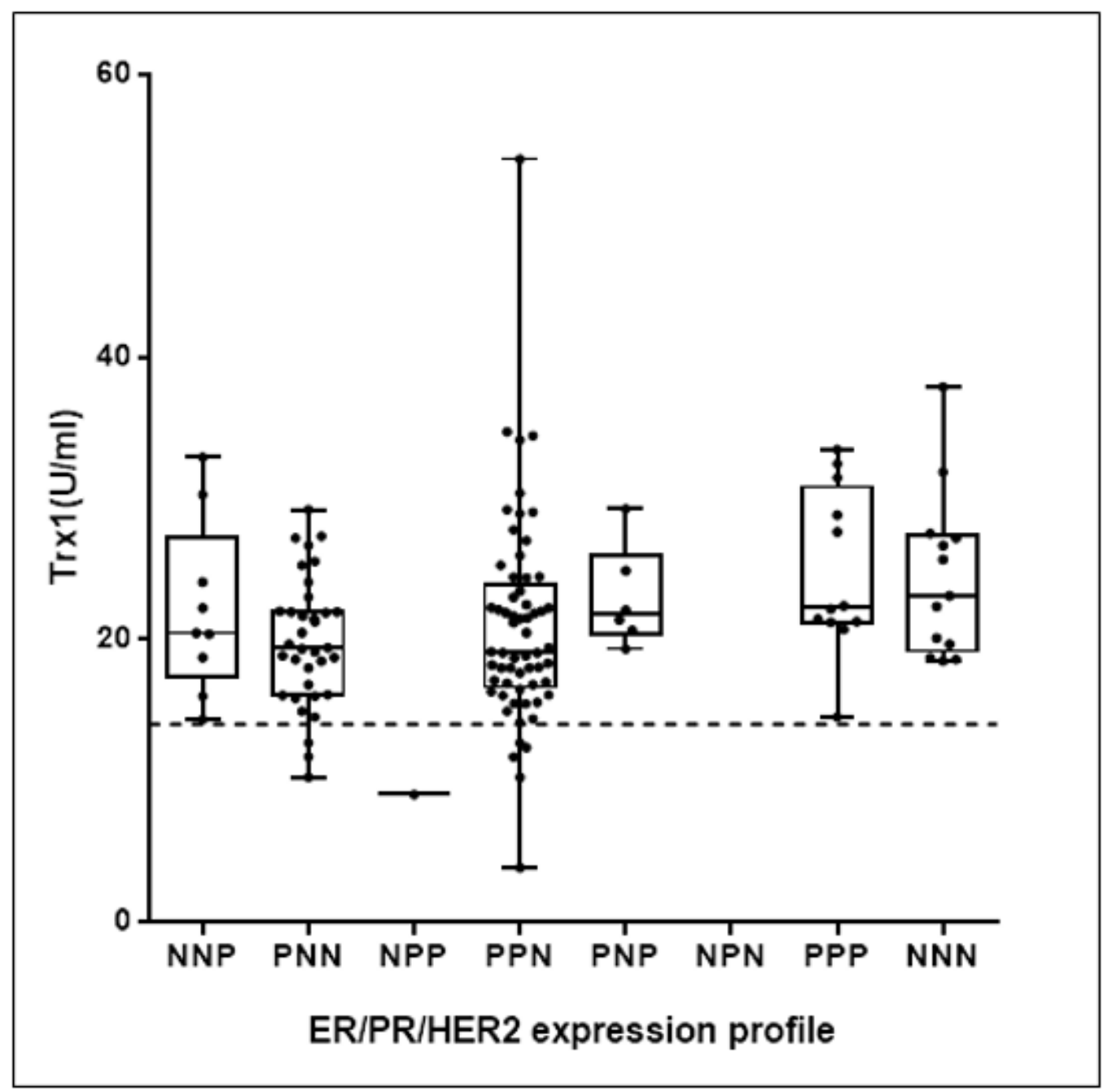

Figure 4

The effect of hormone receptor expression profile on the blood level of Trx 1 Trx 1 level from breast cancer patients were analyzed by the expression profiles of estrogen receptor (ER), progesterone receptor (PR), and human epidermal growth factor receptor 2 (HER2). Three-letter remarks on $x$-axis indicate positive $(P)$ or negative $(\mathrm{N})$ expression of ER, PR, and HER2 in order. For example, PPN indicates ER+, PR+ HER2-. The dotted line indicates the cut-off value of Trx1 level (14.13 Unit/ml). 
A

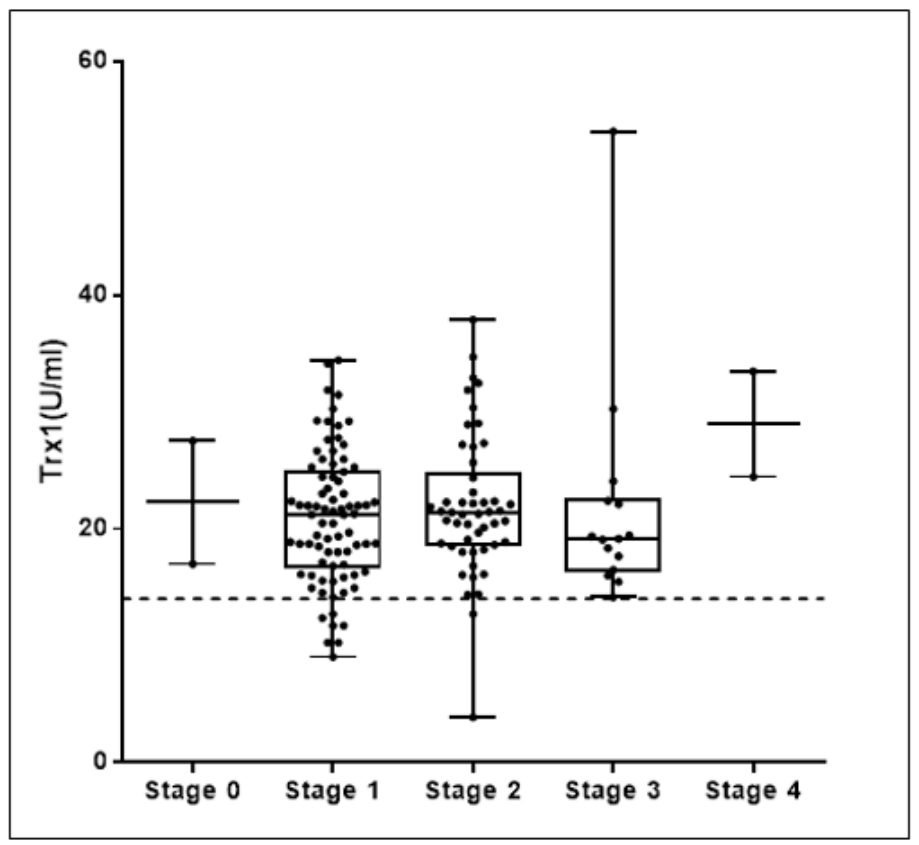

B

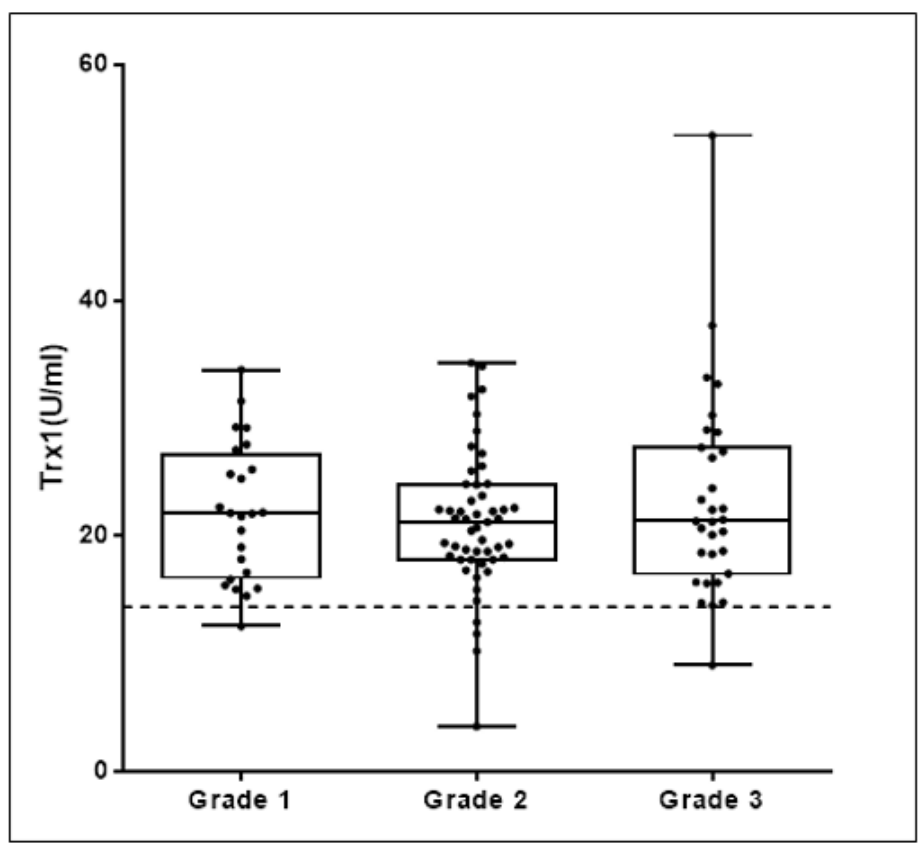

\section{Figure 5}

The effect of breast cancer stage and grade on the blood level of Trx 1 Trx 1 levels from breast cancer patients were analyzed by stage and grade of the cancer. (A) Effect of breast cancer stage. The number of patients at each stage were 2 at stage 1, 37 at stage 1,50 at stage 2, 15 at stage 3, and 2 at stage 4. (B) Effect of breast cancer grade that was assessed by biopsy. The number of patients at each grade were 24 at grade 1, 51 at grade 2 , and 31 at grade 3 . The dotted line indicates the cut-off value of Trx 1 level (14.13 Unit/ml). 


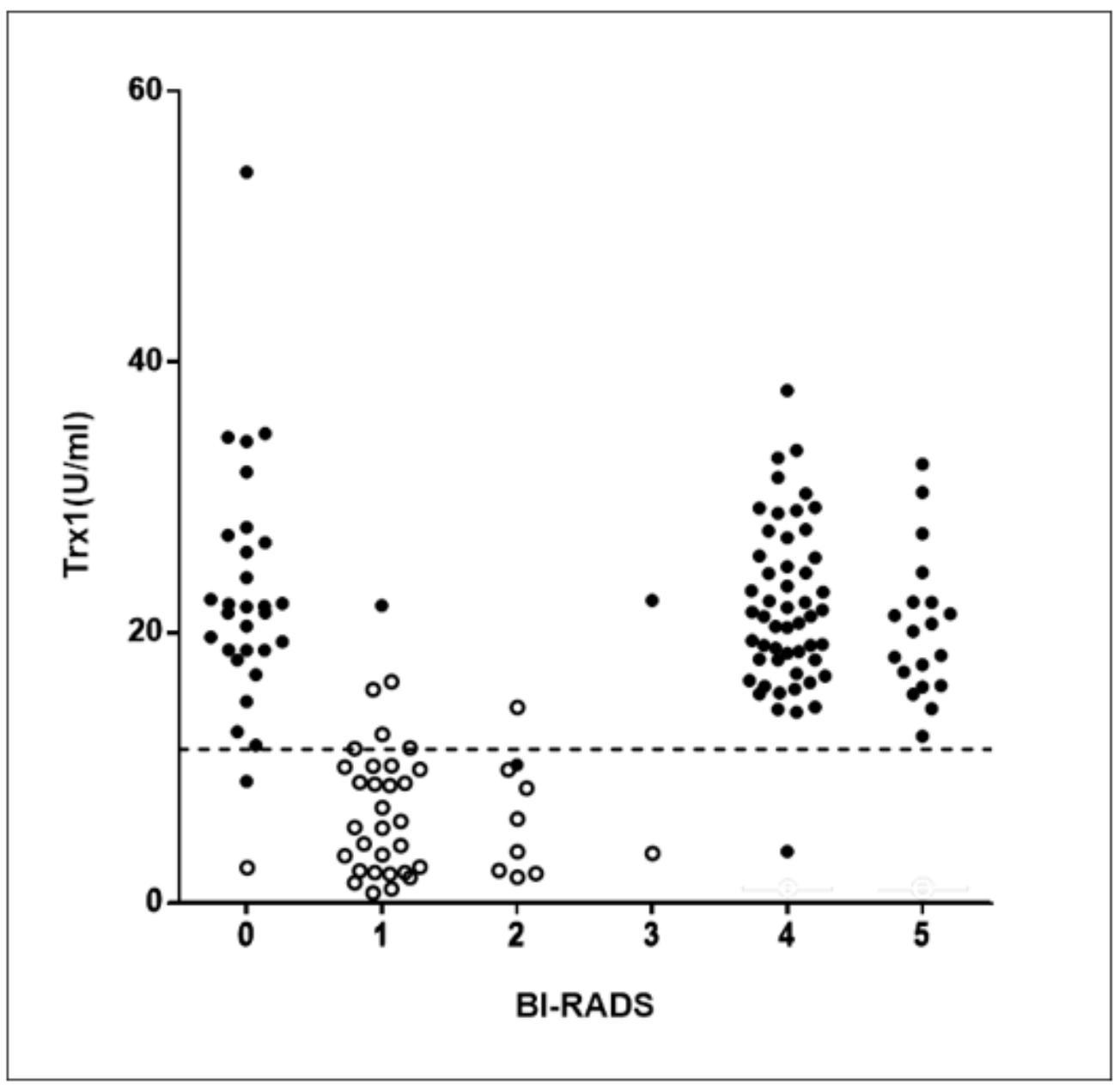

Figure 6

Complementary effect of blood Trx1 level on mammography for higher accuracy BI-RADS category of subject's mammogram and corresponding blood Trx 1 level were analyzed together. A total of 103 biopsy-confirmed BC patients and 42 normal healthy women who submitted mammograms approved by physicians were analyzed. The numbers on the X-axis indicate the categories of the BI-RADS scoring system. The dotted line indicates the cut-off value of Trx1 level (14.13 Unit/ml). Filled circle ( $\bullet$ ), biopsy confirmed BC patients; empty circle ( $(\bullet)$, healthy normal women. + 